\title{
VARIAÇÃo SEDIMENTAR dAS PRAIAS do PinA E BoA ViageM, RECIFE (PE) - BRASIL
}

\author{
MARIA DAS NEVES GREGóRIO ${ }^{1}$ \\ Tereza C. Medeiros de Araújoº \\ LÚCIA M. MAFRA VALENÇA ${ }^{3}$ \\ ${ }^{1}$ Programa de Pós-Graduação em Oceanografia da Universidade Federal de Pernambuco \\ e-mail: nevesgregorio@hotmail.com \\ ${ }^{2}$ Departamento de Oceanografia Universidade Federal de Pernambuco \\ e-mail:tcma@ufpe.br \\ ${ }^{3}$ Departamento de Geologia Universidade Federal de Pernambuco \\ e-mail:lmmv@ufpe.br
}

Recebido: 02/02/04

Aceito: 10/08/04

\begin{abstract}
RESUMO
As praias do Pina e da Boa Viagem localizam-se na cidade do Recife - PE. Com o objetivo de caracterizar a variação sedimentológica destas praias, bem como observar possíveis mudanças sazonais, foram coletadas 13 amostras de sedimentos superficiais ao longo do arco praial nos meses de Junho de 2002 (estação chuvosa) e Dezembro de 2002 (estação seca), durante a maré de sizígia. Os sedimentos passaram pelo peneiramento úmido e seco, utilizando-se um intervalo de peneiras de $1 / 2 \Phi$, no Laboratório de Oceanografia Geológica (UFPE). Os mesmos foram classificados como areia muito fina à média durante a estação chuvosa, e de areia fina à média na estação seca, com areia média ocorrendo apenas na parte central da área. As amostras apresentaram uma predominância de grãos bem selecionados na estação chuvosa, e moderadamente selecionados na estação seca. Houve uma maior ocorrência de curvas aproximadamente simétricas nas duas estações, com maior representatividade no inverno, indicando um ambiente de maior energia. Apresentam distribuições mesocúrtica em ambas estações, sugerindo-se uma mistura no selecionamento dos grãos. Os sedimentos são constituídos por grãos de quartzo (80\%) e material bioclástico (20\%). Os grãos de quartzo variam de subarredondados a arredondados, com alta esfericidade, e textura superficial brilhante, indicando um transporte aquático. $\mathrm{O}$ maior teor de carbonato de cálcio foi encontrado ao norte da área, onde não há presença de recifes.
\end{abstract}

Palavras chaves: Sedimentos, praia, variações sazonais

\section{Abstract}

\section{SEDIMENTARY VARIATION OF THE BEACHES FROM PINA AND BOA VIAGEM, RECIFE (PE) - BRASIL}

The beaches Pina and Boa Viagem are located in Recife city. With objective to caracterize the sedimentary variation of theses beaches, as well to observing seasoning variations, 13 samples of superficial sediments were collected along the beach arch at June (rainy season) and December (dry season) of 2002, during the spring tides. The sediments had passed for a humid and dry screening using an interval of sleve of $1 \frac{2}{2}$ Phy, in Laboratory of Geological Oceanography (UFPE).

Tropical Oceanography, Recife: v. 32, n. 1, p. 39-52, 2004 
The sediments collected along the beach arch were classified as very fine to medium sand during the rainy season, and fine to medium sand during the dry season, with medium sand occurring only the central part of the area. They samples presented a predominance of grains that were selected well in the rainy season. Also they were selected moderately in the dry season. An occurrence of approximately assimetrical curves was observed in the dry and rainy seasons, been more representative in the rainy season, indicating an environment of more energy. The sediments showed mesocurtic distributions in both seasons, suggesting a mixture in the grains selection. The sediments are composed of quartz grains $(80 \%)$ and bioclastic material $(20 \%)$. The grains of quartz vary of sub-rounded to rounded with high sphericity, and shinning superficial texture, indicating an aquatic transport. The major content of carbonate of calcium was found to north of the area, where there are not beach rocks.

Key words: sediments, beaches, seasoning variations

\section{INTRODUÇÃO}

King (1959, apud HOEFFEL, 1998) define uma praia como um ambiente sedimentar costeiro de composição variada, formado comumente por areia, e condicionado pelos sistemas de ondas que incidem sobre a costa. As variações texturais observadas nos sedimentos litorâneos podem estar relacionadas às variações na energia das ondas, taxas de transporte e à influência de diferentes fontes de sedimentos ao longo da praia (KOMAR, 1976 apud ACCIOLY \& DOMINGUEZ, 1997). Segundo Lira (1997), as características texturais de um sedimento podem ser referidas a um conjunto de estatísticas, descritivas de sua distribuição granulométrica associados a tendências centrais (como mediana, média e desvio-padrão) ou caudais (assimetria e curtose).

A investigação dos processos sedimentares com base nas análises granulométricas, vem sendo utilizada para a compreensão da dinâmica sazonal de ambientes sedimentares costeiros recentes (BITTENCOURT; FARIAS; ZANINI JR., 1987). A análise sedimentar visa fornecer subsídios para a correlação entre as características texturais dos sedimentos e dos vários ambientes que compõe a dinâmica deposicional, bem como estabelecer parâmetros utilizáveis na identificação e característica do ambiente (SUGUIO, 1973).

O Estado de Pernambuco apresenta uma faixa costeira de $187 \mathrm{~km}$ que, segundo Manso et al (1995), divide-se em três setores: Norte, Médio e Sul. A cidade do Recife situa-se no Setor Médio da costa pernambucana, sendo o mesmo caracterizado pela sedimentação quaternária. Os depósitos quaternários são constituídos por terraços marinhos do Holoceno, com altitude média de 1 a $5 \mathrm{~m}$ e do Pleistoceno com 7 a 11m; depósitos de pântanos elaborados na última transgressão; bancos de arenitos que afloram em alguns trechos da praia, formados durante níveis marinhos mais elevado; e recifes de corais associados aos bancos de arenitos submersos (DOMINGUEZ et al, 1990).

As praias do Pina e da Boa Viagem localizam-se entre as coordenadas planas UTM $9105000-9098000$ N e 293000 - 289000 E (Figura 1). São formadas por terraços marinhos Holocênicos, tendo como limites às áreas de manguezais, o canal de Setúbal e a linha de costa, constituídas por areias quartzosas claras. Em frente ao Recife, a plataforma continental é estreita e pouco recortada (KEMPF, 1967/9). A natureza de fundo da plataforma apresenta lama, recife de arenito e areia quartzosa. Em um estreito canal entre os recifes se encontra um material fino trazido pelos rios através do estuário de Barra de Jangada, que é transportado para o norte (KEMPF; MABESSONE; TINOCO, 1967/9). Este estudo tem como objetivo caracterizar a variação sedimentológica das praias do Pina e da Boa Viagem, bem como observar possíveis mudanças sazonais. 


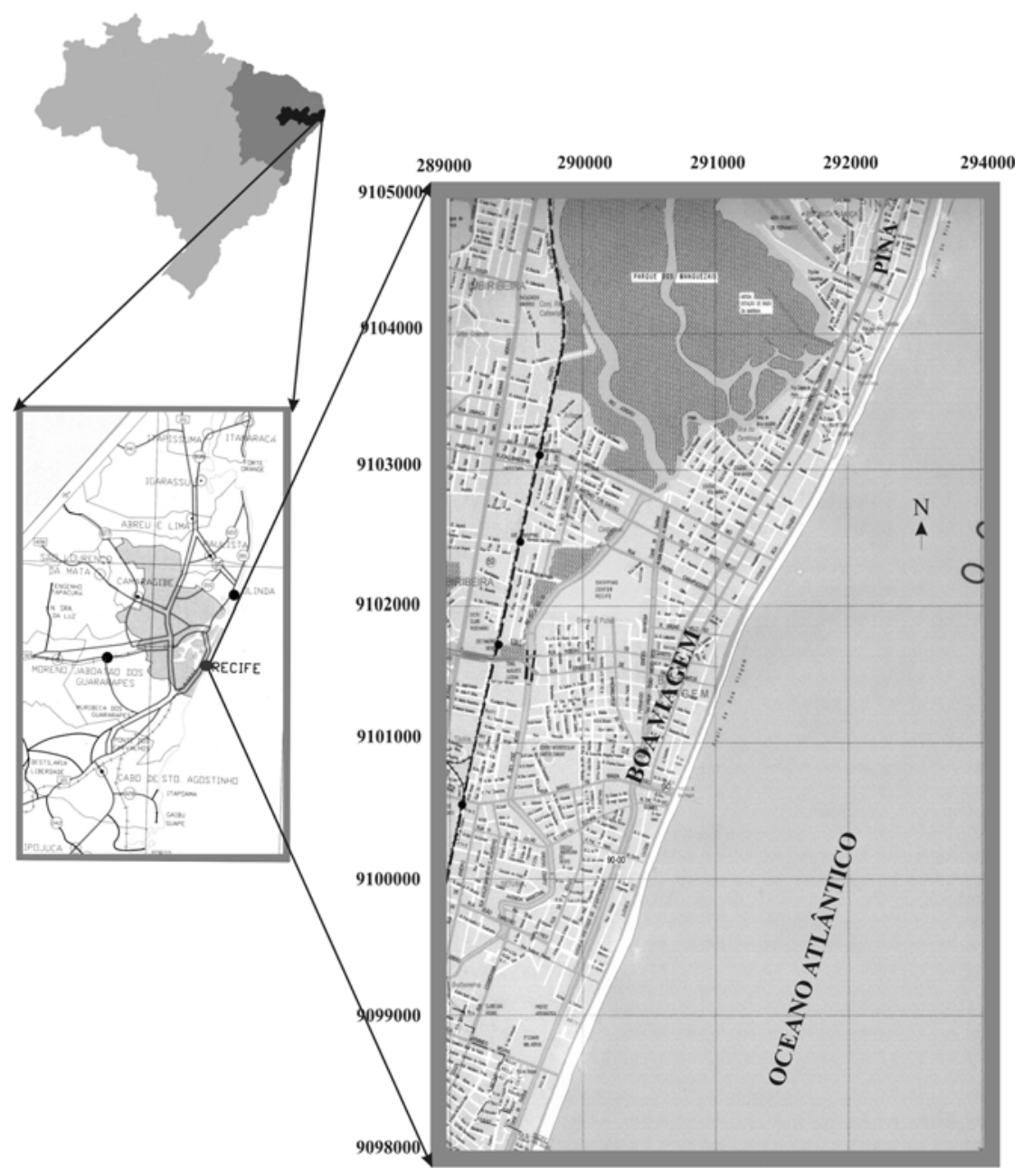

Figura 1 - Localização da área de estudo

\section{Material e Métodos}

Foram coletadas na face da praia, 13 amostras de sedimentos superficiais ao longo do arco praial, nos meses de Junho e Dezembro de 2002, durante a maré de sizígia. As amostras estão distribuídas a uma distância média de 500 metros uma da outra, numeradas de 1 a 13 no sentido Norte/Sul, indo da praia do Pina ao limite dos municípios Recife/Jaboatão dos Guararapes.

Os sedimentos foram analisados segundo a metodologia de Suguio (1973), passando pelo peneiramento úmido e seco, utilizando-se um intervalo de peneiras de $1 / 2 \Phi$, no Laboratório de Oceanografia Geológica, do Departamento de Oceanografia da Universidade Federal de Pernambuco (UFPE).

Os parâmetros estatísticos dos sedimentos estudados foram analisados e definidos segundo o Software SYSGRAM desenvolvido por Camargo's Corp. (1999), e classificados segundo Folk \& Ward (MUEHE, 1996). Os resultados obtidos foram convertidos em informações estatísticas 
descritivas e construídos gráficos com programas específicos. As características morfoscópicas foram determinadas através da lupa binocular, e classificadas segundo a Tabela de Krumbeim \& Sloss (POWERS, 1953 apud SCHOLLE, 1979). Para o estudo morfoscópico foi utilizado 100 grãos na fração 1,0 $\Phi$ para as amostras de 01 a 11, e a fração total para as amostras 12 e 13, por não haver grãos suficientes na fração $1,0 \Phi$ nestas amostras.

O teor de carbonato de cálcio foi determinado pelo método de Loring \& Rantala (1992), o qual consiste no ataque de $\mathrm{HCl}$ a $40 \%$ a frio, para eliminação do $\mathrm{CaCO}_{3}$. Uma alíquota seca de 10 gramas de cada amostra foi atacada com uma solução de ácido clorídrico, depois lavada com água destilada, levada à estufa $\left(60^{\circ} \mathrm{C}\right)$, e novamente pesada. $\mathrm{O}$ valor do teor de $\mathrm{CaCO}_{3}$ foi encontrado pela diferença de peso entre o total da alíquota utilizada e o valor do peso de grãos de quartzo sendo depois calculado o percentual do $\mathrm{CaCO}_{3}$.

\section{RESULTADOS}

Os resultados das análises granulométricas dos sedimentos das estações chuvosa e seca, encontram-se nas figuras abaixo. O tamanho médio do grão encontra-se representado na Figura 2.

No período chuvoso os sedimentos foram classificados de areia muito fina à média. A areia média se encontra na parte central da área de estudo, enquanto a areia fina é encontrada nas extremidades, e areia muito fina (amostra 2) sendo observada apenas ao norte da área. No período seco os sedimentos são dominantemente constituídos por areia fina, com apenas uma amostra sendo classificada como areia média (amostra 5),localizada na parte central.

Em relação ao desvio padrão (Figura 3), as amostras apresentaram uma variação de pobremente selecionada a bem selecionada na estação chuvosa, predominado a classificação bem selecionada, encontrando-se apenas uma amostra pobremente selecionada ao norte. Durante o período seco as amostras variaram de moderadamente a bem selecionada, observando-se a predominância de sedimentos moderadamente selecionados. Apenas duas amostras, foram classificadas bem selecionadas, uma na parte central (amostra 7) e outra no extremo sul (amostra 13).

Quanto à assimetria (Figura 4), as amostras apresentaram uma variação de assimetria de muito negativa a positiva no período chuvoso, observando-se porém uma maior ocorrência do grau de aproximadamente simétrica. Foram observadas apenas duas amostras muito negativa (amostras 02 e 09) e duas positivas (05 e 10), não caracterizando assim, um padrão de distribuição ao longo da área. No período seco, a variação foi de assimetria negativa, a muito positiva. Como já observado na estação chuvosa, não há também um padrão de distribuição para o verão.

Em relação a curtoses (Figura. 5), na estação chuvosa predominaram os valores médios de curtose, de mesocúrtica a platicúrtica, Porém, observou-se uma maior ocorrência de mesocúrtica distribuídas ao longo da área de estudo. No período do verão, as amostras também apresentaram uma maior ocorrência de distribuições mesocúrticas, concentradas ao centro e ao sul da área, seguidas de platicúrtica localizadas ao norte.

Os resultados obtidos das análises morfoscópica e composicional encontram-se nas Tabelas 1 e 2 referentes aos períodos chuvoso e seco, respectivamente. Os sedimentos são constituídos por $80 \%$ por grãos de quartzo e $20 \%$ de material bioclático. Os grãos de quartzo foram classificados de subarredondados a arredondados, predominando grãos arredondados, com maior expressão na estação seca. As amostras que apresentaram grãos subarredondados encontram-se na parte central da área, na estação chuvosa, e apenas uma amostra (amostra 2) na estação seca. Os grãos de quartzo apresentaram alta esfericidade e brilhantes nas duas estações. Os componentes bioclásticos são constituídos por foraminíferos, fragmentos de conchas, espinhos de equinodermatas, algas calcárias, gastrópodes e tubos de poliquetas.

A análise do teor carbonato de cálcio revelou que, durante a estação chuvosa, os valores variaram de $2,2 \%$ a $32 \%$ (Figura. 8 ). Os maiores valores são encontrados no extremo norte da área 
(valores entre $24 \%$ a $32 \%)$, enquanto os menores teores foram encontrados na parte central $(2,2 \%$ a $7 \%$ ). Na parte sul predominou valores intermediários (entre 10\% a 14\%).

Para estação do verão, os valores variaram de $10 \%$ a $37 \%$, tendo sido observado um acréscimo no teor de carbonato de cálcio para a maioria das amostras. Como na estação do inverno, os maiores teores de carbonato (Figura. 8) também são encontrados na porção norte da área estudada, com valores intermediários nas porções centrais e sul da área.

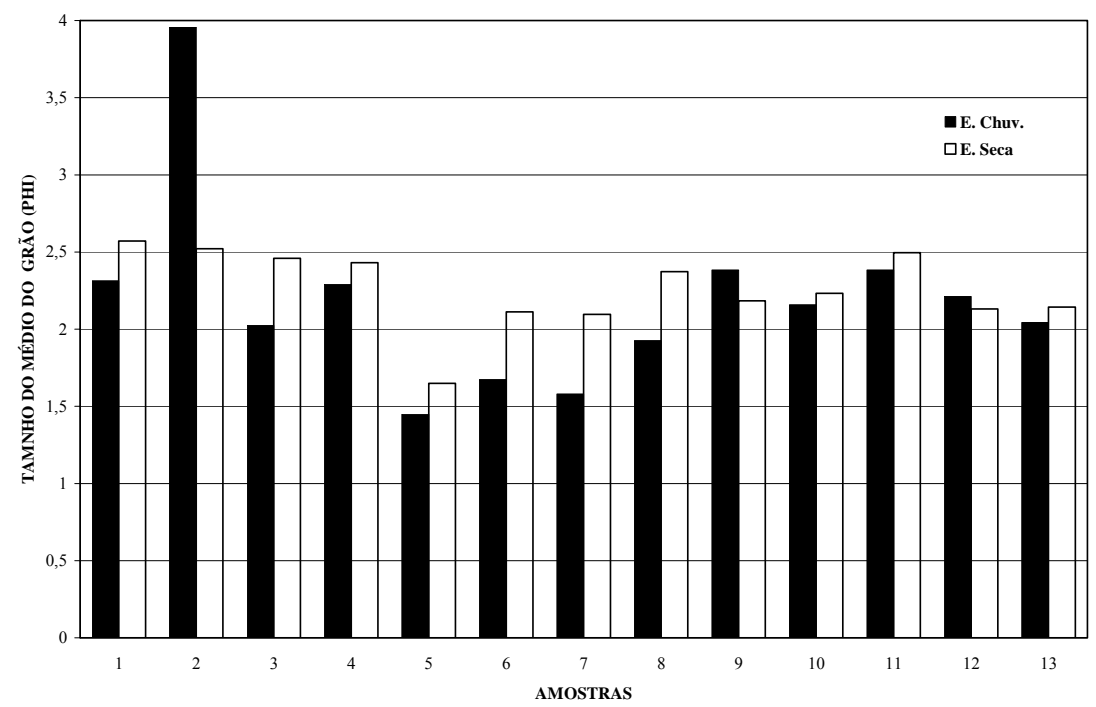

Figura 2 - Variações do tamanho médio dos grãos, nas duas estações. 


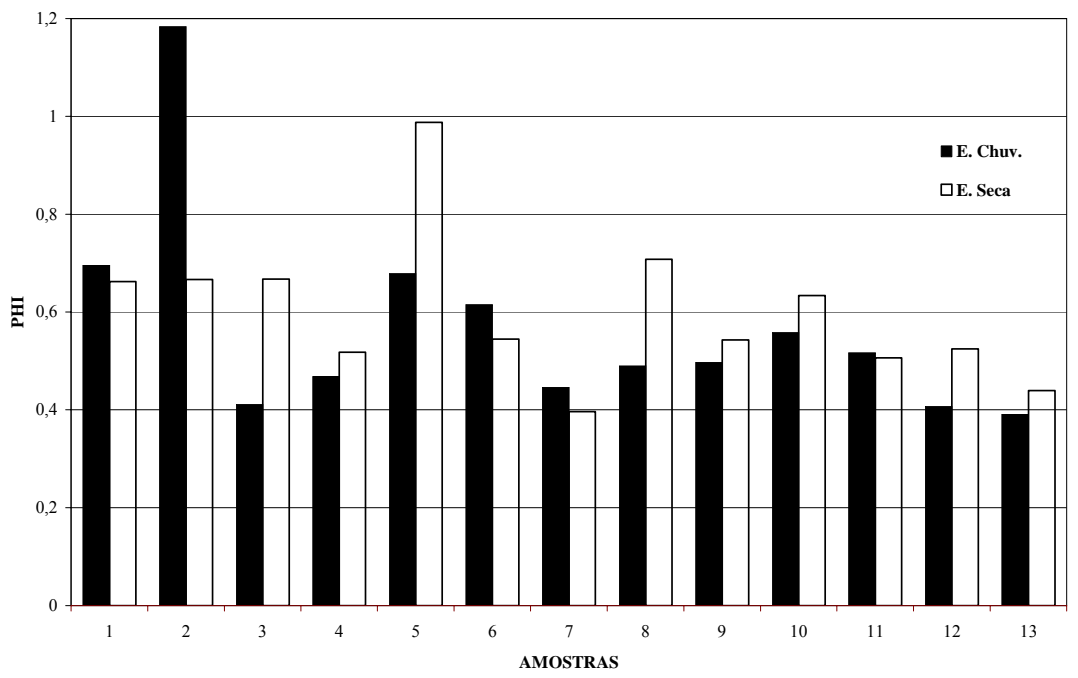

Figura 3 - Variações de desvio padrão, nas duas estações.

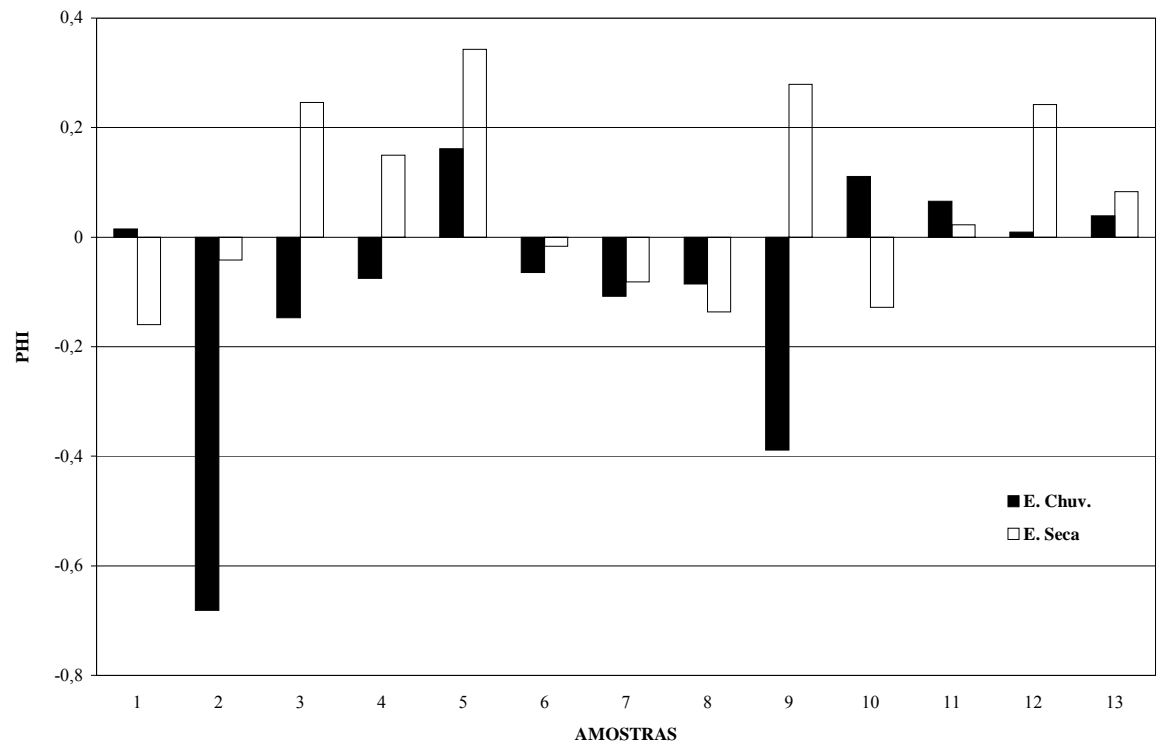

Figura 4 - Variações de assimetria, nas duas estações. 


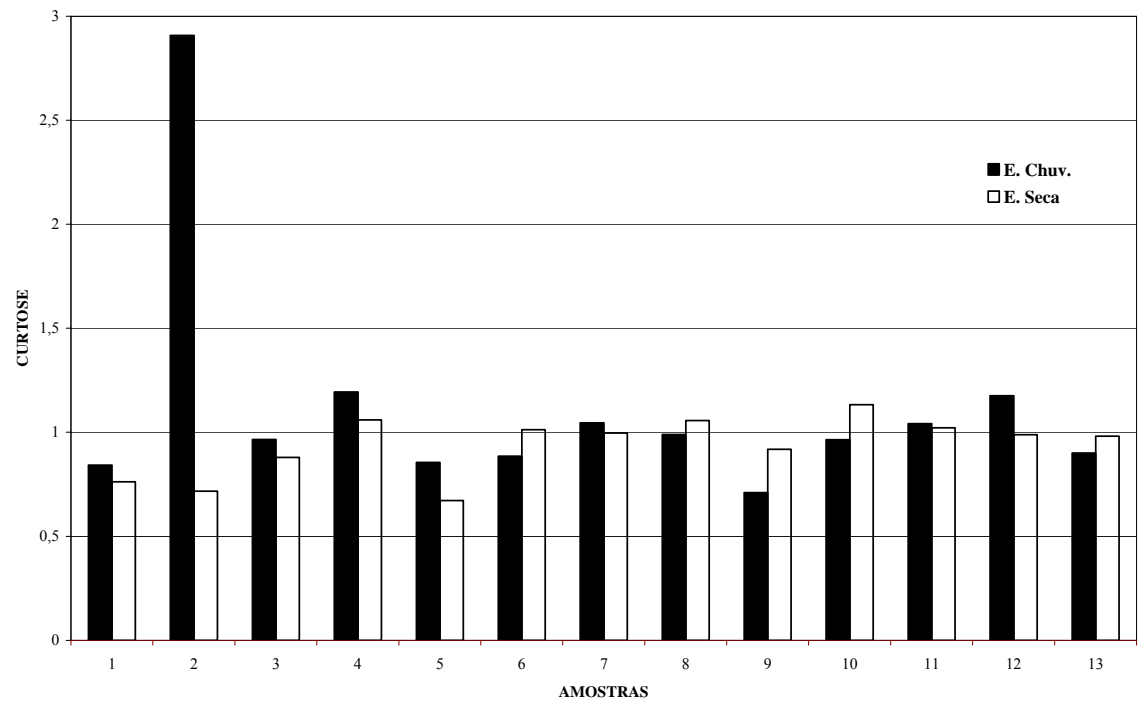

Figura 5 - Valores de curtose nas duas estações.

Tabela 1 - Resultados dos estudos morfoscópicos do mês de Jun/2002.

\begin{tabular}{|c|c|c|c|c|c|c|c|c|c|}
\hline \multirow{2}{*}{ Amotras } & \multicolumn{2}{|c|}{ Arredondamento } & \multicolumn{2}{c|}{ Esfericidade } & \multicolumn{2}{c|}{$\begin{array}{c}\text { Textura Super. } \\
\text { Superficial }\end{array}$} & \multicolumn{2}{c|}{ Composição } \\
\cline { 2 - 9 } & Sar & Ar & Bar & Alta & Baixa & Fosca & Brilhante & Qz & Bio \\
\hline 1 & & $\bullet$ & & $\bullet$ & & & $\bullet$ & $\bullet$ & $\bullet$ \\
\hline 2 & & $\bullet$ & & $\bullet$ & & & $\bullet$ & $\bullet$ & $\bullet$ \\
\hline 3 & & $\bullet$ & & $\bullet$ & & & $\bullet$ & $\bullet$ & $\bullet$ \\
\hline 4 & & $\bullet$ & & $\bullet$ & & & $\bullet$ & $\bullet$ & $\bullet$ \\
\hline 5 & $\bullet$ & & & & $\bullet$ & & $\bullet$ & $\bullet$ & $\bullet$ \\
\hline 6 & $\bullet$ & & & & $\bullet$ & & $\bullet$ & $\bullet$ & $\bullet$ \\
\hline 7 & $\bullet$ & & & $\bullet$ & & & $\bullet$ & $\bullet$ & $\bullet$ \\
\hline 8 & $\bullet$ & & & $\bullet$ & & & $\bullet$ & $\bullet$ & $\bullet$ \\
\hline 9 & & $\bullet$ & & $\bullet$ & & & $\bullet$ & $\bullet$ & $\bullet$ \\
\hline 10 & & $\bullet$ & & $\bullet$ & & & $\bullet$ & $\bullet$ & $\bullet$ \\
\hline 11 & & $\bullet$ & & $\bullet$ & & & $\bullet$ & $\bullet$ & $\bullet$ \\
\hline 12 & & $\bullet$ & & $\bullet$ & & & $\bullet$ & $\bullet$ & $\bullet$ \\
\hline 13 & & $\bullet$ & & $\bullet$ & & & $\bullet$ & $\bullet$ & $\bullet$ \\
\hline
\end{tabular}

Arredondamento: Composição:

Subarredondado - Sar Quartzo - Qz

Arredondado - Ar Bioclástico - Bio

Bem arredondado - Bar 
Tabela 2 - Resultados dos estudos morfoscópicos do mês de Dez/2002.

\begin{tabular}{|c|c|c|c|c|c|c|c|c|c|}
\hline \multirow[t]{2}{*}{ Amotras } & \multicolumn{3}{|c|}{ Arredondamento } & \multicolumn{2}{|c|}{ Esfericidade } & \multicolumn{2}{|c|}{$\begin{array}{c}\text { Textura Superficial } \\
\text { Superficial }\end{array}$} & \multicolumn{2}{|c|}{ Composição } \\
\hline & Sar & Ar & Bar & Alta & Baixa & Fosca & Brilhante & $\mathbf{Q z}$ & Bio \\
\hline 1 & & • & & • & & & • & $\cdot$ & • \\
\hline 2 & • & & & • & & & • & - & • \\
\hline 3 & & $\bullet$ & & $\bullet$ & & & $\bullet$ & - & $\bullet$ \\
\hline 4 & & $\bullet$ & & $\bullet$ & & & $\bullet$ & - & • \\
\hline 5 & & $\bullet$ & & $\bullet$ & & & $\bullet$ & - & • \\
\hline 6 & & $\bullet$ & & $\bullet$ & & & $\bullet$ & - & • \\
\hline 7 & & $\bullet$ & & $\bullet$ & & & $\bullet$ & - & • \\
\hline 8 & & $\bullet$ & & $\bullet$ & & & $\bullet$ & - & $\bullet$ \\
\hline 9 & & $\bullet$ & & $\bullet$ & & & $\bullet$ & $\cdot$ & $\cdot$ \\
\hline 10 & & $\bullet$ & & $\bullet$ & & & $\bullet$ & $\cdot$ & $\cdot$ \\
\hline 11 & & $\bullet$ & & $\bullet$ & & & $\bullet$ & - & $\cdot$ \\
\hline 12 & & $\bullet$ & & $\bullet$ & & & $\bullet$ & $\cdot$ & $\cdot$ \\
\hline 13 & & $\cdot$ & & $\cdot$ & & & $\cdot$ & $\cdot$ & $\cdot$ \\
\hline
\end{tabular}

Arredondamento: Composição:

Subarredondado - Sar Quartzo - Qz

Arredondado - Ar Bioclástico - Bio

Bem arredondado - Bar

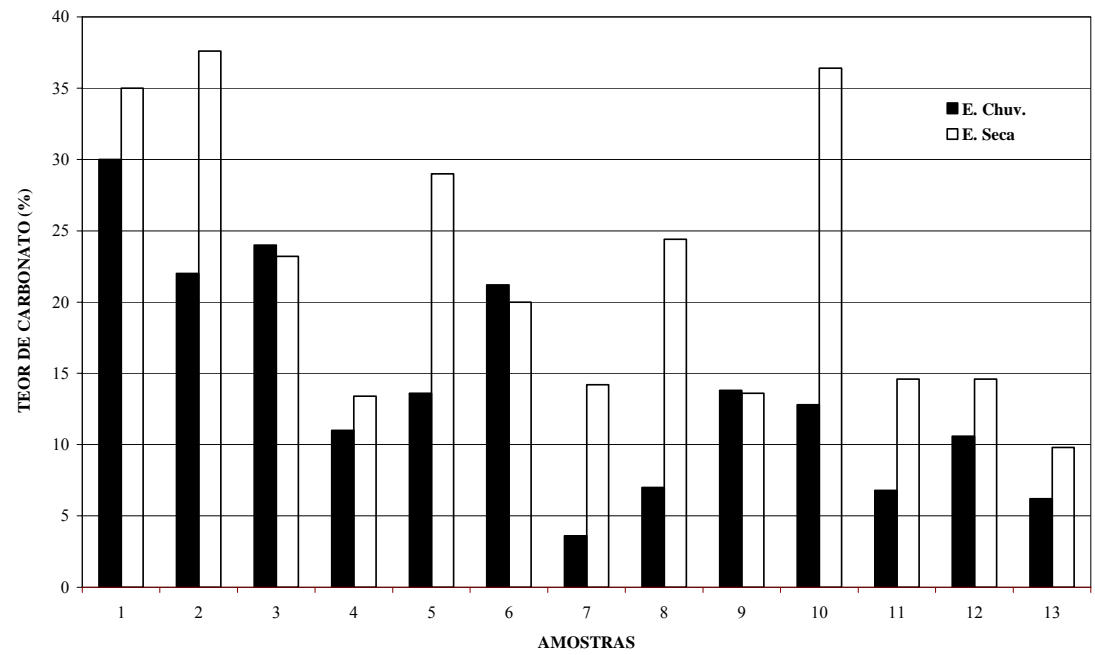

Figura 6 - Variações do teor de $\mathrm{CaCO}_{3}$ nas duas estações. 


\section{DISCUSSÃO}

Os resultados granulométricos dos sedimentos, bem como o teor de carbonato de cálcio, em sua distribuição espacial, encontram-se sumarizados nas Figuras 7 e 8.

Os resultados granulométricos obtidos servem para comparações entre as amostras, para desenvolvimento ou teste de comportamento dos sedimentos durante o transporte e deposição, interpretação das condições de gênese e/ou mapeamento das variações das características sedimentológica (SUGUIO, 1973). O tamanho do grão depende da natureza do material envolvido, do tempo e distância do transporte.

A média é uma medida que fornece a distribuição do tamanho médio do grão (TOLDO, JR., 1988). Segundo a classificação Wentworth (1922 apud MUEHE, 1996), são classificados de cascalhos a areia muito fina.

As amostras apresentaram uma predominância de areia fina em ambos períodos (Figura. 7), evidenciando que não houve uma grande variação de energia entre o período chuvoso e seco. No entanto a presença de areia média na parte central é devido, possivelmente, à ocorrência de pequenas aberturas entre os recifes neste segmento, que permitem a remoção dos sedimentos finos pela ação das ondas incidentes durante o período chuvoso

A presença de areia fina ao norte da área, pode ser esclarecida pela ocorrência de recifes submersos que dissipem a energia das ondas incidentes neste local, ou pela retirada dos grãos da região de dunas frontais para a região da praia pelo vento.

O desvio padrão é uma medida de dispersão, que determina o grau de seleção dos sedimentos, que são classificados segundos os limites, de muito bem selecionados a extremamente mal selecionados (MUEHE, 1996). Na estação chuvosa os sedimentos analisados apresentaram um melhor selecionamento, com a predominância das amostras em serem bem selecionadas, havendo portanto uma maior influência da energia das ondas neste período. Ao contrário na estação seca foi observada a predominância de sedimentos moderadamente selecionados em quase todo ambiente (Figura. 7). Apenas duas amostras foram classificadas como bem selecionadas, uma na parte central e outra no extremo sul. Assim, no verão não houve um ambiente de energia suficiente para um bom selecionamento dos grãos, como observado na estação chuvosa. Segundo Russell (1939 apud SUGUIO, 1973), a seleção pode se processar pela ação de três tipos de mecanismos diferentes: seleção local (durante a deposição), seleção progressiva (durante o transporte), ou as duas ao mesmo tempo.

A assimetria é uma medida da tendência dos dados de se dispersarem de um ou outro lado da média (SUGUIO, 1973). Curvas simétricas são representadas, quando os sedimentos são constituídos por material fino e grosso em proporções iguais. A assimetria é o parâmetro granulométrico que melhor caracteriza o ambiente, principalmente ao nível energético do mesmo (MABESOONE, 1968). Segundo Duane (1964 apud CPRH, 1998), o sinal negativo indica remoção de partículas finas (ou remoção seletiva contínua), característico de praias, zonas litorâneas e canais de entrada de maré. $O$ sinal positivo resulta da acumulação de sedimentos finos em zonas protegidas, como lagunas e dunas de deposição eólicas (LIRA, 1997). Em relação aos processos de deposição, as praias apresentam uma assimetria negativa, devido os componentes finos serem mais facilmente removidos pelo vento.

Nos sedimentos estudados, foi observada uma maior ocorrência do grau de aproximadamente simétrico, não apresentando um padrão de distribuição ao longo da área (Figura 8), nas duas estações. De modo geral, os sedimentos foram classificados como aproximadamente simétricos em ambos os períodos, havendo uma maior representatividade no período chuvoso, indicando assim uma mistura dos grãos durante os períodos chuvoso e seco, e que não houve grande diferença de energia no período chuvoso para a retirada dos grãos mais finos. A área de estudo não apresenta distribuições freqüentemente encontradas em ambientes de praias (assimetria negativa). 


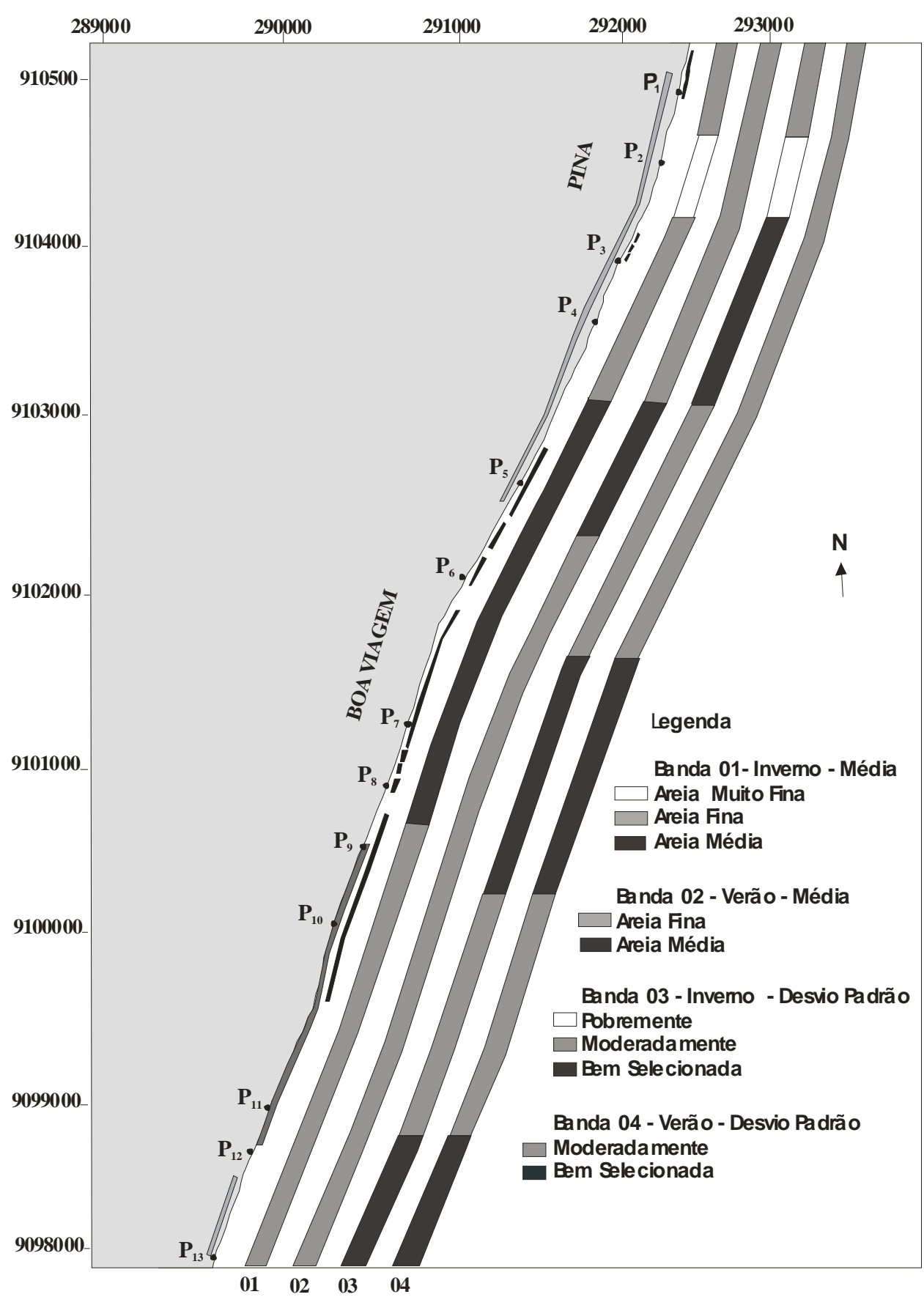

Figura 7 - Distribuição espacial do tamanho médio do grão e desvio padrão, nas duas estações. 


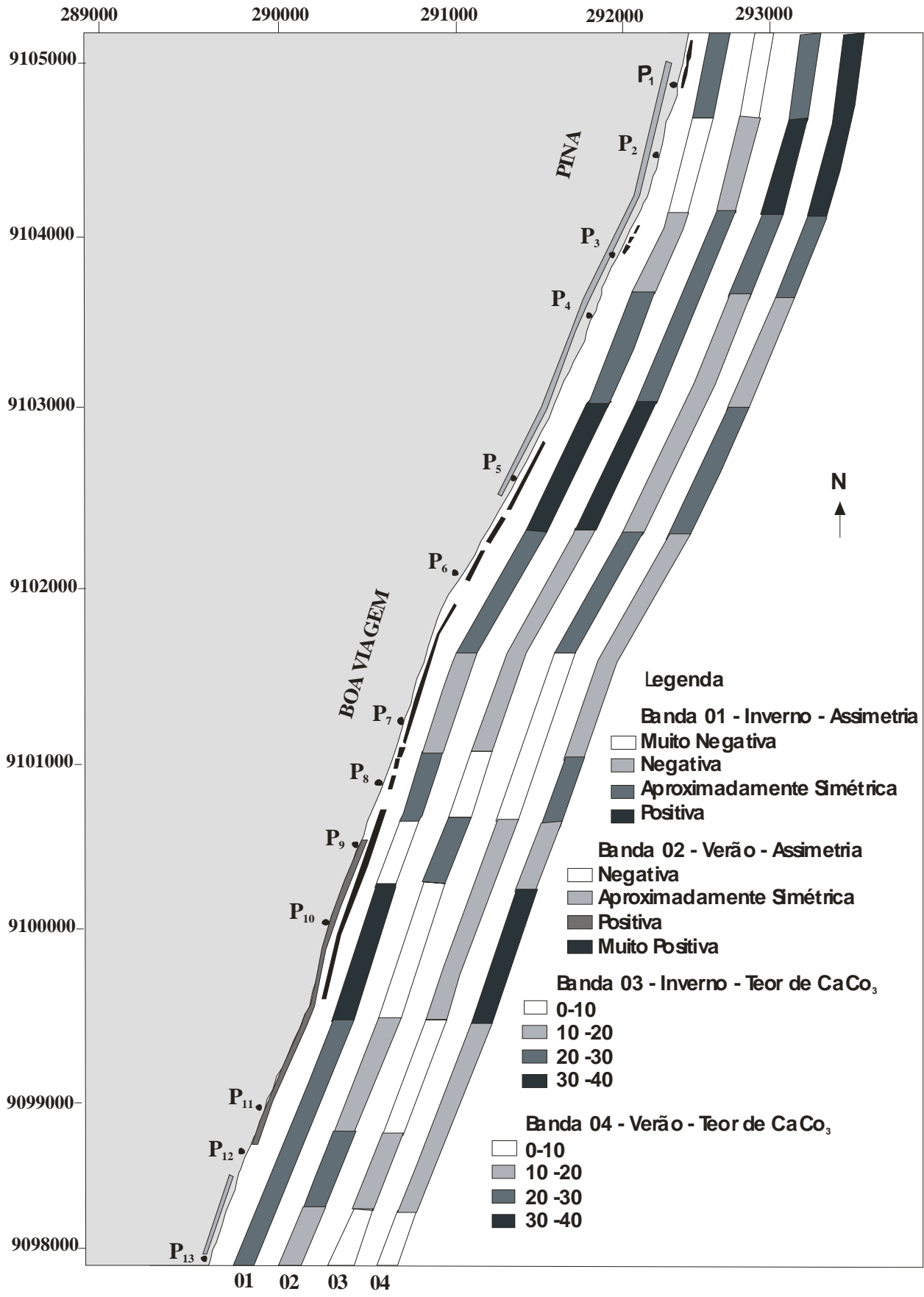

Figura 8 - Distribuição espacial de assimetria e teor de carbonato de cálcio, nas duas estações 
A curtose é uma medida que retrata o grau de agudez dos picos das curvas de distribuição, ou seja o grau de seleção dos extremos comparando-os com a parte central (MUEHE, 1996). São classificados segundo os limites de variação, de muito platicúrtica a extremamente lepotocúrtica.

Em relação à curtose, para os sedimentos na estação chuvosa predominaram valores médios de curtose, com uma maior ocorrência de distribuições mesocúrticas ao longo área de estudo. Durante a estação seca foi observado, também, uma maior ocorrência de distribuições mesocúrticas, concentradas ao centro e ao sul da área de estudo. Valores muitos altos ou muitos baixos de curtose podem sugerir que um tipo de material foi selecionado em uma região de alta energia, e então transportado sem mudança das características do ambiente (SUGUIO, 1973). Segundo Lima Santos (1998), os valores de curtose estão relacionados às condições de movimentação do ambiente sedimentar. As amostras que apresentam distribuições leptocúrtica e muito leptocúrtica são de ambientes de maior movimentação; platicúrtica e muito platicúrtica são de ambientes de baixa movimentação; e distribuições mesocúrticas, de ambientes de mais ou menos movimentação. Para as praias do Pina e da Boa Viagem, predominaram distribuições mesocúrticas em ambas as estações, indicando um ambiente de energia intermediária.

Em relação à composição, os sedimentos analisados são constituídos essencialmente por grãos de quartzo nas duas estações. Os componentes bioclásticos encontrados nas duas estações, são representados por foraminíferos; fragmentos de conchas, espinhos de equinodermatas, gastrópodes, tubos de poliquetas.

Segundo Mabesoone (1968), a morfometria compreende o estudo da forma (esfericidade e arredondamento) das partículas sedimentares. Esses parâmetros dependem do transporte, bem como do rigor do transporte. De acordo com Ponzi (1995), o fator da forma controla parcialmente o comportamento dos seixos durante o transporte e deposição; a angulosidade e o arredondamento refletem a distância e o rigor do transporte. Nos sedimentos analisados foi observado, que a maioria dos sedimentos apresentou uma dominância de grãos de quartzo com alta esfericidade nas duas estações, como também uma maior expressão de grãos arredondados, tendo estes uma dominância maior na estação seca.

O uso do arredondamento como índice de maturidade foi sugerido por Pettijhon (1957), principalmente nos sedimentos inconsolidados. O grau de maturidade com índices mais altos resulta de grãos arredondados e esféricos. Assim, os grãos de quartzo encontrados são considerados grãos maturos.

A textura superficial pode se: Sacoroidal (fosca ou polida), mamelonada (fosca ou polida), lisa (fosca ou polida) que é expressa pela presença ou ausência de brilho. Os grãos que apresentam superfícies polidas indicam superfícies homogêneas e lisas e refletem o máximo de luz incidente, os de superfícies foscas é resultado da difusão da luz (MABESOONE, 1968). O polimento é atribuído ao suave retrabalhamento por agente abrasivo de granulação muito fina, apresentam superfícies lisas e polidas, e são de origem aquáticas (TOLDO JR., 1998). As amostras analisadas são constituídas dominantemente por grãos de quartzo brilhantes nas duas estações, indicando um transporte de origem aquática.

$\mathrm{Na}$ análise do teor de carbonato de cálcio foi observado que, na estação chuvosa (Figura. 8), os maiores teores se localizam no extremo norte da área, e os menores valores foram observados na parte central. Valores intermediários predominaram na parte sul.

Para a estação seca foi observado um aumento no teor de carbonato de cálcio para a maioria das amostras. Como na estação chuvosa, os maiores valores do teor de carbonato de cálcio (Figura 8) foram também encontrados na porção norte da área de estudo, com valores intermediários nas porções centrais e sul da área.

Em relação à distribuição espacial de norte para o sul (Figura 8), os menores valores de teor de carbonato de cálcio observados na parte central e sul da área, indicam uma correlação entre o teor de carbonato e as áreas abrigadas por beach rocks. Nestas, a contribuição de material oriundo da plataforma continental é menor, predominando os sedimentos de origem quartzosa. Ao norte da 
área de estudo, onde predominam praias abertas, são observados os maiores valores de teor de carbonato de cálcio, havendo portanto uma maior contribuição da plataforma continental.

\section{CONCLUSÃo}

Em relação ao tamanho médio dos grãos, os sedimentos foram classificados de areia fina à média, sendo a areia média encontrada no centro da área, com maior ocorrência na estação chuvosa.

Em relação ao grau de seleção, há uma predominância das amostras em serem moderadamente selecionadas, sendo que na estação chuvosa os grãos mostram um melhor selecionamento.

A assimetria apresentada pelas amostras indica uma tendência dos grãos em curvas aproximadamente simétricas durante as estações chuvosa e seca, tendo esta uma maior representatividade durante a estação chuvosa.

O grau de agudez das curvas de distribuição mostra a predominância de curvas mesocúrticas, indicando uma mistura nos tamanhos dos grãos durante o selecionamento. A presença de distribuição platicúrtica ao Norte da área, provavelmente está relacionada à presença de recife submerso, que permita um ambiente de menor energia e menor movimentação.

Os sedimentos das praias do Pina e da Boa Viagem, são constituídos em $80 \%$ por grãos de quartzo e $20 \%$ por fragmentos bioclásticos. Os grãos bioclásticos são constituídos por carapaças de foraminíferos, fragmentos de conchas, espinhos de equinodermatas, algas calcárias gastrópodes, tubos de poliquetas. Os grãos de quartzo são em sua maioria arredondados. Apresentam alta esfericidade, são brilhantes, indicando um transporte de origem aquática, e grãos maturos.

Os menores valores de teor de carbonato de cálcio são encontrados na parte central e sul da área, $\mathrm{Na}$ parte norte encontra-se os maiores valores de carbonato de cálcio em ambos estações. Na estação seca, foi observado um aumento no teor de carbonato de cálcio para a maioria das amostras.

\section{REFERÊNCIAS BIBLIOGRÁFICAS}

ACCIOLY, P. C. V.; DOMINGUEZ, J. M. L. Mudanças sazonais nos parâmetros texturais dos sedimentos praias, entre Juá e Arembepe, litoral Norte do Estado da Bahia. CONGRESSO DA ASSOCIAÇÃO BRASILEIRA DE ESTUDOS DO QUATERNÁRIO E REUNIÃO SOBRE O QUATERNÁRIO DA AMÉRICA DO SUL, 6. 1997, Curitiba, Anais... Curitiba 1997, p. 19 - 23.

BITTENCOURT, A. C. S. P.; FARIAS, F. F. F.; ZANINI JR., A.. Reflexo das variações morfodinâmicas praiais nas características texturais dos sedimentos da praia da Armação, Salvador, Bahia. Revista Brasileira de Geociências, 1987. p. 276 - 282.

CPRH, Companhia Pernambucana do Meio Ambiente. Secretaria de Ciência, Tecnologia e Meio Ambiente. Estudo da erosão marinha na região de Maracaípe - Ipojuca. Recife. 1998. 98 p.

DOMINGUEZ. J. M.. L.; BITTENCOURT, A. C. S. P.; LEÃO, Z. M. A. N.; AZEVEDO, A. E. G. Geologia do quaternário costeiro do Estado de Pernambuco. Revista Brasileira de Geociências, 1990. vol. 20, p. 208 - 215.

HOEFFEL, F. G. Morfodinâmica de praias arenosas oceânicas, uma revisão bibliográfica. Editora Univali, Itajaí: Santa Catarina, 1998. 82 p.

KEMPF, M. A plataforma continental de Pernambuco (Brasil). Trabalhos Oceanográficos. Universidade Federal de Pernambuco. Recife, 1967/69. p. 111-119. 
KEMPF, M.; MABESSONE, M. J.; TINOCO, I. M. Estudo da plataforma continental na área do Recife (Brasil). Trabalhos Oceanográficos, Universidade Federal de Pernambuco, Recife, 1967/69. p. $125-148$.

LIRA, A. R. A. Caracterização morfológica e vulnerabilidade do litoral entre as praias da Enseadinha e Maria Farinha, Paulista - PE. Recife, 1997. 96f. Dissertação (Mestrado em Geociências) - Departamento de Geociências. Universidade Federal de Pernambuco.

LIMA SANTOS, R. C. A. Estudos sedimentológicos e geoambiental no sistema Lagunar Mundaú - Alagoas. Recife, 1998. 127f. Dissertação (Mestrado em Geociências) - Departamento de Geociências. Universidade Federal de Pernambuco

LORING, G. H.; RANTALA, R. T. T., Manual for the geochemical anlyses of marine sediments ands suspended particulate matter. Earth Sei. 1992. Rew.; 32: p. 235 - 283.

MABESOONE. J. M. Sedimentologia, Universidade Federal de Pernambuco - Recife, 1968. 473 p.

MANSO, V. A. V.; COUTINHO, P. N.; LIMA, A.T. O.; MEDEIROS, A. B.; ALMEIDA, L. E. S. B.; BORBA, A. L. S.; LIRA, A. R. A. PEDROSA, F. J. A.; CHAVES, N.S.; DUARTE, R. X.; IVO, P. S. Estudos da erosão marinha na praia da Boa Viagem. Convênio ENLURB/FADE/LGGM UFPE. Relatório Técnico, Recife, 1995. 98 p.

MUEHE, D. Geomorfologia costeira. 1996. In: GUERRA, A. J. T.; CUNHA, S. B. Geomorfologia: exercícios, técnicas e aplicação. Rio de Janeiro: Bertrand Brasil. 1996. p. 253 - 306.

PETTIJOHN, F. J. Rocas sedimentary. Editorial Universitária de Buenos Aires. Buenos Aires, 1970.731p.

PONZI, V. R. Métodos de análises sedimentológicas de amostras marinhas. Representações de resultados através de gráficos e mapas. UFPE. Instituto de Geociências. 1995. 35 p.

SCHOLLE, P. A. Constituents, textures, cements, and porosities of sandstones and associate rocks. U. S. Geological Survey, Published by The American Association of The American Association of Petroleum Geologists Foundation. Tulsa, Oklahoma, U. S. A., 1979. 193 p.

SUGUIO, K. Introdução à sedimentologia. São Paulo, Editora Edgar Blucer, da Universidade de São Paulo, 1973. 312 p.

TOLDO JR., E.E. Sedimentologia 1. Instituto de Geociências, Departamento de Mineralogia e Petrografia, Universidade Federal do Rio Grande do Sul. Porto Alegre, 1998. 52 p. 